\title{
The need to publish and the birth of predatory medical journals
}

\author{
Alejandra Castañón-González¹, Jaime Javier Cantú-Pompa², Alejandro Miranda-Hernández³ \\ and Julio César López-Valdés ${ }^{4}$ \\ ${ }^{1}$ Hospital Infantil de México Federico Gómez, Ciudad de México; ${ }^{2}$ School of Medicine, Tecnológico de Monterrey, Monterrey , N.L.; ${ }^{3 P}$ rivate Pediatric \\ Hospital, Ciudad de México; ${ }^{4}$ Surgeon, Facultad de Medicina de Tampico Dr. Alberto Romo Caballero, Universidad Autónoma de Tamaulipas, \\ Tampico, Tamps. Mexico
}

\section{Dear Editor,}

First of all, we would like to thank for the time bestowed on reading this writing. However, the reason for this letter is to dare bringing up our concerns with regard to a problem that has been growing and that we consider has to be addressed: the birth of predatory journals, the expansion of which has been of exponential characteristics over the past few years and that, in addition, have defined an area of medical literature that attempts to deceive authors and readers. Although throughout the world they have been the subject of controversy, both in Mexican and Spanish-speaking medical literature there are no recommendations or records about them. Having said this, the authors consider there is the need to generate a precedent to alert those readers who are still unaware about the topic..

While high academic competition has forced the new generations to broaden their ambitions not only within the clinical field but also to dabble in the area of medical research, the appearance of the Internet Phenomenon has originated a radical transformation of academic publications thanks to the emergence of parallel electronic versions of higher diffusion; however, as Shen and Björk document ${ }^{1}$, this particularity gave way to a side effect: the new perspective for a radical reconsideration by publishers as providers of services for authors (e.g., review by experts on the subject, edition and even publication itself), and not as systems to spread knowledge. This is how, in this model, authors pay publishers for "open access" service for universal distribution ${ }^{2,3}$. However, far from representing a favorable change, this has caused for the integrity of produced evidence to be compromised, since poorly ethical publications, called predatory journals ${ }^{1-4}$, have emerged, the main purpose of which is to profit from charges to process manuscripts. All this, together to the fact that current professional scenario is a rapidly changing setting, where research is an essential requirement for eligibility for job promotions, has caused for the need to publish to be highly increased; in a few words, predatory journals exploit a fundamental weakness in academic research: the need of an investigator to publish papers to move forward on his or her career and authors who yearn for immediate good results fall in the trap. In addition, writers who report in these periodicals are at risk of wasting their effort, since the websites of this kind of journals can disappear at any moment.

Commonly, these "pseudoscientific" journals promote themselves using attractive or similar names to those of legitimate academic publications and are accompanied by inflated or inexistent metrics through personalized invitations by e-mail, where they promise expedite review with short publication time. However, this kind of publishing houses has no interest in scientific quality or work soundness. Even though detecting this type of literature would appear to be easy, recognizing it in practice is more complicated; for this reason, in recent years, academician Professor Jeffrey Beall ${ }^{3}$, with the purpose to alert the scientific community about this danger, as well as to reduce the

\author{
Correspondence: \\ Julio César López-Valdés \\ Salvador Diaz Miron, 203 Oriente \\ Despacho 302, Ddificio Josmar \\ Zona centro C. P. 8900 Tampico \\ Tamps, Mexico \\ E-mail: jc.lopz@live.com
}

Date of reception: 08-05-2017

Date of acceptance: 17-05-2017

DOI://dx.doi.org/10.24875/GMM.M17000032
Gac Med Mex. 2017;153:472-473

Contents available at PubMed www.gacetamedicademexico.com 
corruption of the open access system, published a list (Beall's list $)^{5}$ where all those journals and publishing houses highly suspected of fraudulent and academically discreditable practices are included. It should be mentioned that the list has been updated over time, and in some cases, not only open access publishers whose practices are consistent with characteristics belonging to "predatory literature" have been added to the directory. Due to this, around the world, "Beall's list" has been regarded as a milestone for initial screening in the selection of a publishing house (or even a journal) as holder of the results obtained after performing a research work. However, concurrently, these journals have prompted the emergence of "predatory authors ${ }^{6}$," who use to publish false articles or poorly detailed investigations with low reproducibility, with the purpose to "pump up" their academic curriculum ${ }^{6,7}$. In turn, this academic drop originates a sort of chaotic phenomenon when used by other scientists for research, with the bases of their investigations sometimes ending up being established on uncertain publications.
Therefore, the authors consider there is an urge to generate awareness and warn the readers on the existence and proliferation of these practices lacking ethics and undeserving of medicine ${ }^{6-8}$. In the same token, we advise the academicians to read available reviews on the subject, as well as evaluations and descriptions in several articles.

\section{References}

1. Shen C, Björk BC. 'Predatory' open access: a longitudinal study of article volumes and market characteristics. BMC Medicine. 2015;13:230.

2. Masten YB, Ashcraft AS. The dark side of dissemination: traditional and open access versus predatory journals. Nurs Educ Perspect. 2016;37:275-7.

3. Beall J. Predatory journals threaten the quality of published medical research. J Orthop Sport Phys Ther. 2017;47:3-5.

4. Clemons M, De Costa e Silva M, Joy AA, et al. Predatory invitations from journals: more than just a nuisance? Oncologist. 2017;22:236-40.

5. Beall J. Beall's list of predatory publishers. Scholarly Open Acces. (Consultado el 20 de enero de 2017.) Disponible en: https://scholarlyoa. com/2016/01/05/bealls-list-ofpredatory-publishers-2016.

6. Narimani M, Dadkhah M. Predatory journals and perished articles; a letter to editor. Emergency. 2017;5:e49.

7. Beall J. Best practices for scholarly authors in the age of predatory journals. Ann R Coll Surg Engl. 2016;98:77-9.

8. Beall J. Dangerous predatory publishers threaten medical research. J Korean Med Sci. 2016;31:1511-3. 